\title{
Intercostal, ilioinguinal, and iliohypogastric nerve transfers for lower limb reinnervation after spinal cord injury: an anatomical feasibility and experimental study
}

\author{
${ }^{*}$ Ahmed A. Toreih, MD, ${ }^{1}$ Asser A. Sallam, MD, PhD, ${ }^{1}$ Cherif M. Ibrahim, MD, ${ }^{2}$ Ahmed I. Maaty, MD, ${ }^{3}$ \\ and Mohsen M. Hassan ${ }^{4}$ \\ Departments of ${ }^{1}$ Orthopedic Surgery and Trauma and ${ }^{3}$ Physical Medicine, Rheumatology, and Rehabilitation, Suez Canal \\ University Hospitals; ' 2 Department of Anatomy, Suez Canal University; and ${ }^{4}$ Department of Surgery, Anesthesiology, and \\ Radiology, Faculty of Veterinary Medicine, Suez Canal University, Ismailia, Egypt
}

\begin{abstract}
OBJECTIVE Spinal cord injury (SCI) has been investigated in various animal studies. One promising therapeutic approach involves the transfer of peripheral nerves originating above the level of injury into those originating below the level of injury. The purpose of the present study was to evaluate the feasibility of nerve transfers for reinnervation of lower limbs in patients suffering SCI to restore some hip and knee functions, enabling them to independently stand or even step forward with assistive devices and thus improve their quality of life.
\end{abstract}

METHODS The feasibility of transferring intercostal to gluteal nerves and the ilioinguinal and iliohypogastric nerves to femoral nerves was assessed in 5 cadavers. Then, lumbar cord hemitransection was performed below L1 in 20 dogs, followed by transfer of the 10th, 11th, and 12th intercostal and subcostal nerves to gluteal nerves and the ilioinguinal and iliohypogastric nerves to the femoral nerve in only 10 dogs (NT group). At 6 months, clinical and electrophysiological evaluations of the recipient nerves and their motor targets were performed.

RESULTS The donor nerves had sufficient length to reach the recipient nerves in a tension-free manner. At 6 months postoperatively, the mean conduction velocity of gluteal and femoral nerves, respectively, increased to $96.1 \%$ and $92.8 \%$ of the velocity in controls, and there was significant motor recovery of the quadriceps femoris and glutei.

CONCLUSIONS Intercostal, ilioinguinal, and iliohypogastric nerves are suitable donors to transfer to the gluteal and femoral nerves after $\mathrm{SCl}$ to restore some hip and knee motor functions.

https://thejns.org/doi/abs/10.3171/2018.8.SPINE181

KEYWORDS nerve transfer; intercostal nerve; ilioinguinal nerve; iliohypogastric nerve; spinal cord injury

$\mathrm{T}$ Raumatic spinal cord injury (SCI) global incidence rates range from 13 to 53 cases per million population. ${ }^{2}$ Although there is a balanced male-to-female ratio in pediatric reports, ${ }^{1,27}$ adult studies mainly demonstrate a minimum male-to-female ratio of $2: 1$, with some reporting much higher rates. ${ }^{2}$ Two common age-associated peaks are evident in traumatic SCI incidence rates: in young adulthood (20-29 years for males and 15-19 years for females) and in older age ( $>70$ years for males and $>$ 60 for females). ${ }^{2}$ It has been noted that the cervical spine is most commonly injured (36.2\%), followed by the thoracic $(34.3 \%)$ and then lumbar $(29.5 \%)$ spines. The loss of motor and sensory function following complete SCI remains a frustrating problem. Despite initial medical and surgical therapies, poor recovery is common. ${ }^{33}$
An acute complete lower thoracic SCI (below the level of the L1 spinal cord segment) has been investigated in various animal studies. Peripheral nerve transfers to bypass the zone of injury showed encouraging outcomes. Intercostal neurotizations (T9-T12) have been anticipated by some authors ${ }^{31,32,39,40}$ to be either transferred to the lumbar roots ${ }^{33}$ or directly implanted into the spinal canal. ${ }^{24}$ The harvested intercostal nerve length was sufficient to accomplish these transfers. ${ }^{34}$ Brown et al. also reported in their human cadaveric study the possibility of utilizing the ilioinguinal nerve (L1), or even the iliohypogastric nerve (T12-L1), as a donor to reinnervate the pelvic nerve after SCI. ${ }^{4}$

Our long-term goals are to develop surgical approaches to reinnervate the hip and knee so that patients with $\mathrm{SCI}$ affecting the lower limb nerves can regain control of

ABBREVIATIONS ASIS = anterosuperior iliac spine; EMG = electromyography; MAP = motor action potential; $\mathrm{NT}$ = nerve transfer; $\mathrm{SCl}=\mathrm{spinal}$ cord injury. SUBMITTED January 4, 2018. ACCEPTED August 8, 2018.

INCLUDE WHEN CITING Published online November 23, 2018; DOI: 10.3171/2018.8.SPINE181.

${ }^{*}$ A.A.T. and A.A.S. contributed equally to this article. 
knee extension as well as hip abduction and extension, enabling them to stand independently or even step forward with assistive devices, freeing them from reliance on a wheelchair and thus improving their quality of life. In the present study, we evaluate the anatomical feasibility and the clinical outcome of intercostal, iliohypogastric, and ilioinguinal nerve transfer to reinnervate the gluteal nerves and femoral nerve in cadaveric and animal models, respectively.

\section{Methods}

\section{Cadaveric Study}

Five formalin-fixed cadavers ( 1 female and 4 male, mean age 30.5 years, range $25-33$ years), used for teaching, were dissected bilaterally to expose the intercostal, ilioinguinal, and iliohypogastric nerves, along with femoral and superior and inferior gluteal nerves. The cadavers were inspected to ensure that the following anatomy was intact: 1) ilioinguinal region and upper thigh; 2) lower, lateral thoracic wall; and 3) the lumbosacral plexus.

With the cadaver in a supine position, an ilioinguinal approach was used to identify the ilioinguinal nerve (Fig. 1 left). The iliohypogastric nerve originates from the same lumbar spinal cord segment (L1) as the ilioinguinal nerve, and the 2 nerves have a similar path and diameter. Both nerves emerge through the internal abdominal oblique muscle and can be explored near the anterosuperior iliac spine (ASIS) before traveling between the internal and external abdominal oblique muscles. The iliohypogastric nerve terminates at the midline, while the ilioinguinal nerve passes through the external inguinal ring. The femoral nerve was explored through the same ilioinguinal approach used to identify the donor nerves near the midpoint from the ASIS. Then the cadaver was placed in the true lateral position and a lateral thoracic approach be- tween 11th and 12th ribs was used to identify and expose intercostal nerves (Fig. 1 right). The anterior division of the 9th, 10th, and 11th intercostal nerves and the subcostal nerves were dissected from the lateral border of the paraspinal muscle to its termination in the abdominal muscles. The gluteal nerves were explored through a posterior approach to the hip. After gentle splitting of the gluteus maximus muscle in line with its fibers, the superior and inferior gluteal nerves could be identified at the upper and lower border of pyriformis muscle, respectively.

Ease of access and ability to transfer the intercostal nerves through a subcutaneous tunnel at the posterior axillary line and then beneath the gluteus maximus muscle to the superior and inferior gluteal nerves for restoration of hip abduction and extension was assessed. When assessing the feasibility of transferring the ilioinguinal and iliohypogastric nerves to the femoral nerve, the fascicular anatomy of the femoral nerve should be taken into consideration. Femoral nerve branches to the pectineus muscle, sartorius muscle, and sensory nerves (saphenous and medial cutaneous) branch first and medially, while the vastus medialis, vastus intermedius, and vastus lateralis muscles are centrally located, and the rectus femoris muscle is lateral. ${ }^{14}$ Therefore, the donor nerves would be sutured to the central and lateral motor fascicles of the femoral nerve, which are responsible for quadriceps femoris innervation that maintains knee extension and a stable independent standing position, together with reinnervated hip extensors.

The distance between nerve endings was measured to determine if a direct neurorrhaphy would be possible. For intercostal to gluteal nerve transfer: the distance between the lower border of the rib at the posterior axillary line and a point about $3 \mathrm{~cm}$ cranial to the tip of greater trochanter was determined using measuring tape. ${ }^{3}$ For ilioinguinal and iliohypogastric to femoral nerve transfer: the distance between the ASIS and a midpoint of the inguinal ligament

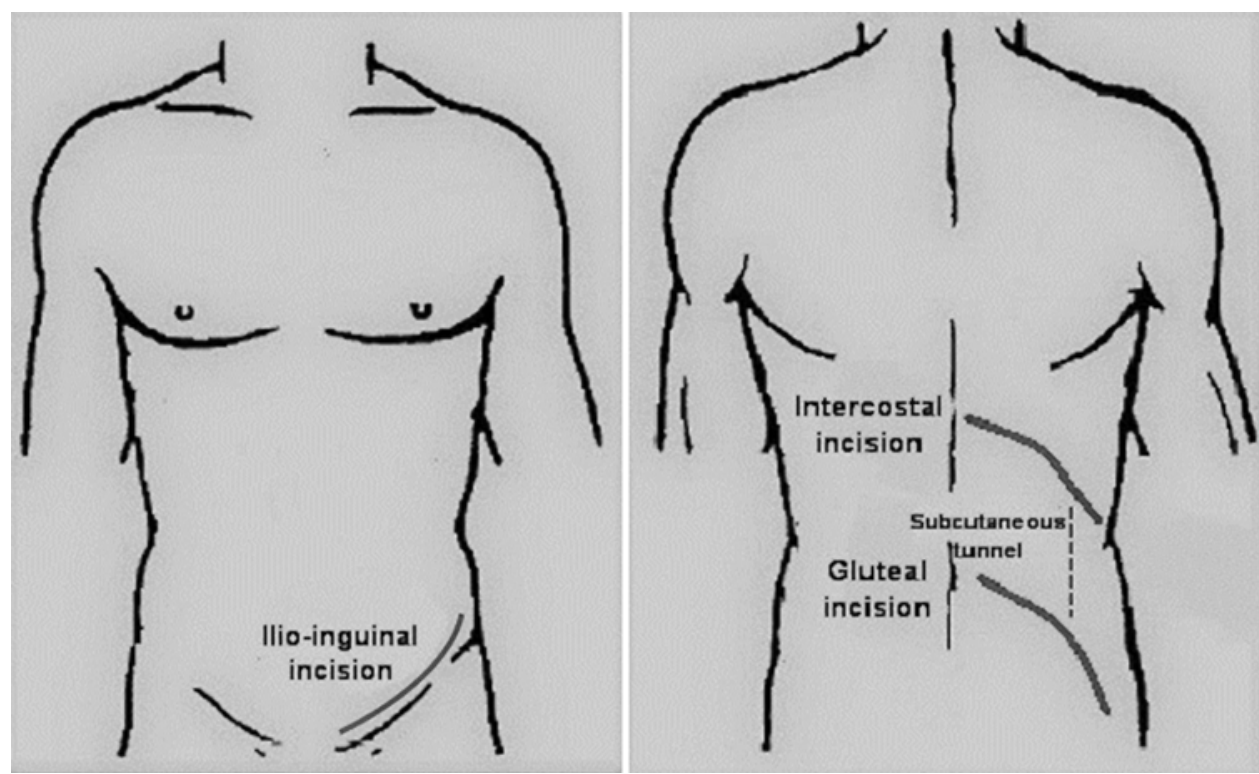

FIG. 1. Illustrations depicting the surgical incisions used in the cadaver study. Left: The ilioinguinal incision for ilioinguinal and iliohypogastric to femoral nerve bypass surgery. Right: The surgical incisions and the subcutaneous tunnel for intercostal to gluteal nerve bypass surgery. 
was determined using measuring tape..$^{14}$ The mean of 3 values was calculated and recorded.

The cross-sectional areas of the nerves were determined by making thin cross-sections with a scalpel, placing these onto microscope slides, and then determining the cross-section areas by using a bright-field dissecting microscope. Digital images of each cross-section were obtained through a microscope at $5 x$ to $10 x$ and analyzed using Canvas X 16 technical illustration software (ACD Systems). The fascicular count for all donor and recipient nerves was recorded. The digital images of the nerve section were analyzed using ImageJ (National Institutes of Health). ${ }^{29}$ Each donor or recipient nerve was manually outlined in ImageJ software, and the cross-sectional area was calculated.

\section{Animal Study}

This study was carried out on 22 healthy adult male mongrel dogs (age 12-18 months) at the Department of Veterinary Surgery, Faculty of Veterinary Medicine, Suez Canal University. All dogs were kept under the same management and nutritional regimens during the study. Food was withheld for 6-8 hours before the operation. Each dog was premedicated with intramuscular injection of chlorpromazine hydrochloride at a dose of $1 \mathrm{mg} / \mathrm{kg}$. General anesthesia was induced by intravenous administration of thiopental sodium $2.5 \%$ solution until the main reflexes disappeared. A full ethical review and approval from the institutional review board of Suez Canal University were obtained prior to the commencement of the study. These animals were not used in any other experimental pro- tocol. The study was performed in accordance with the standards detailed in the Guide for the Care and Use of Laboratory Animals (Institute for Laboratory Animal Research). Two dogs died on the 2nd postoperative day-one because of infection and the other from respiratory distress-and were excluded from the study. This left a total of $20 \mathrm{dogs}$ available for evaluation and data analysis.

Two stages of the investigation were scheduled. The first stage involved performing right lumbar cord hemisection below the level of L1 in all dogs. The second stage was based on the anatomical feasibility study and was performed at the same time of cord hemisection to complete the following nerve transfers (NTs) in only 10 dogs (NT group), taking into consideration that dogs have 13 ribs and 12 intercostal nerves and 1 subcostal nerve. To restore hip abduction and extension, the 10th, 11th, and 12th intercostal nerves and the subcostal nerve were transferred to the cranial gluteal and caudal gluteal nerves. To restore knee extension, the ilioinguinal and iliohypogastric nerves were transferred to the femoral nerve and sutured to the middle and lateral motor fascicles that innervate the quadriceps femoris muscle. ${ }^{14}$ The other 10 dogs underwent no nerve transfers and were used for comparison (control group).

Using an ilioinguinal approach, we identified the femoral nerve lateral to the femoral sheath. The ilioinguinal and iliohypogastric nerves were explored near the ASIS, where they supply the abdominal muscles, and divided at that point to be transferred to the central and lateral motor fascicles of the femoral nerve (Fig. 2). The animals were then placed in a lateral position. Two small transgluteal incisions were performed to explore the caudal and cranial
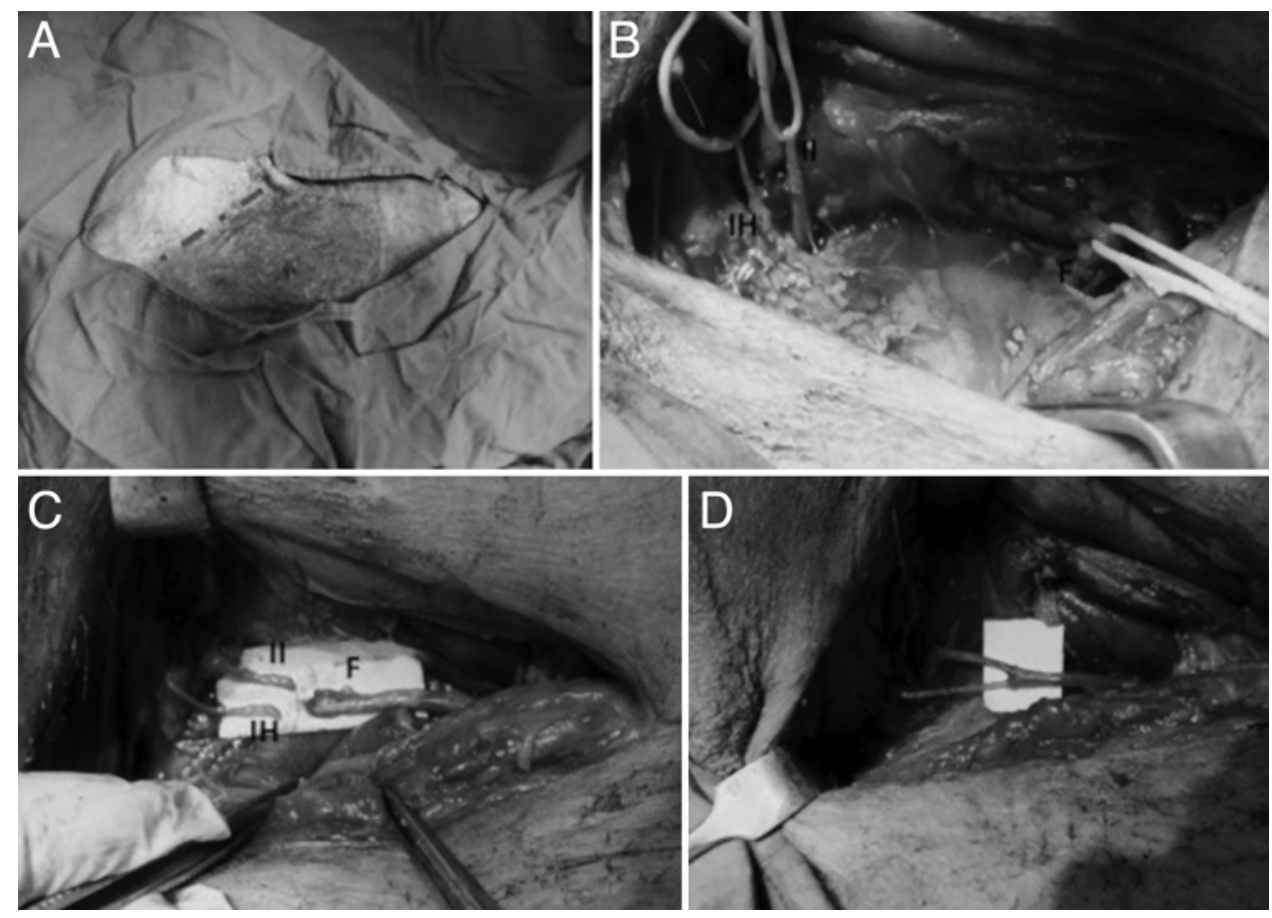

FIG. 2. Transfer of the ilioinguinal and iliohypogastric to the femoral nerve in a dog. A: The incision was made just distal to the inguinal ligament. B: Identification of ilioinguinal (II), iliohypogastric $(\mathrm{IH})$, and femoral $(\mathrm{F})$ nerves. C: The ilioinguinal and iliohypogastric nerves were divided as distally as possible and transferred to the femoral nerve, which was divided as proximally as possible to allow for a tension-free repair. D: The completed anastomosis. 
gluteal nerves. A second $25-\mathrm{cm}$ lateral thoracic incision was made between 12th and 13th ribs. The 10th, 11th, and 12th intercostal nerves and the subcostal nerve were explored and divided as distally as possible, then rerouted subcutaneously for transfer to the divided gluteal nerves (Fig. 3). Identification of all donor and recipient nerves was confirmed by means of an intraoperative disposable nerve stimulator with a current of 1 to $2 \mathrm{~mA}$ (Anaestim MK III Nerve Stimulator; Meda). All nerve repairs were performed under an operating microscope with 2 epineural stay sutures using a 9-0 nylon suture in a tension-free manner. The repair sites were then secured with fibrin glue. All surgical procedures were performed by authors with substantial experience in orthopedic surgery and microsurgery (A.A.T. and A.A.S.), using the same technique.

At the end of each surgical procedure, the wound was closed by conventional technique without a suction drain. Each dog had a clinical follow-up examination every month for 6 months.

Our outcome measures included lameness, thigh circumference, presence of pain, complications, and electrophysiological testing. The animal selection and clinical follow-up were carried out in cooperation with the Veterinary Teaching Hospital, Suez Canal University, Ismailia.

Lameness was evaluated on a scale from 0 to $4(0$, no lameness; 1 , mild lameness or minor gait abnormality; 2 , moderate lameness or gait abnormality; 3 , severe weightbearing lameness; 4, non-weight-bearing lameness). ${ }^{23}$ The thigh circumference was measured at the midpoint on the long axis of the femur between the greater trochanter and the lateral femoral condyle using a single standard plastic metric tape with the dogs positioned in lateral recumbency. The mean of 3 thigh circumference values was calculated and recorded. Pain was assessed by palpation of the pelvic limbs and spine.

Electrophysiological assessment of the femoral and gluteal nerves was performed under general anesthesia at 6 and 12 weeks as well as at 6 months postoperatively and compared to the baseline measurements recorded before surgery. Electrical stimulation was applied with the constant-current electrical stimulator (Endomed 982; Enraf-Nonius). ${ }^{26}$ Two 30 -mm-diameter adhesive electrodes were used for the stimulation of the denervated muscles. Electrodes (an anode and a cathode) were placed over the muscle in its longitudinal plane, with the active electrode at the muscle belly and the reference electrode at the tendon of the muscle. Monophasic triangular pulses were applied to the denervated muscle to determine the threshold intensity (in milliamperes) with visible muscle contraction and joint movement. The current intensity was raised sequentially by $0.1 \mathrm{~mA}$ per second. Testing was performed with a frequency of $1 \mathrm{~Hz}$. Each trial for testing a combination of stimulation parameters continued between 1 and 2 minutes (depending on the threshold intensity). The duration of recovery was twice the duration of one trial. Preprocedure needle electromyography (EMG) was carried out to evaluate the femoral nerve supplying the quadriceps femoris muscle, the superior gluteal nerve supplying the gluteus medius, and the inferior gluteal nerve supplying the gluteus maximus. The EMG was carried out by a clinical rheumatologist with specific neurophysiol-
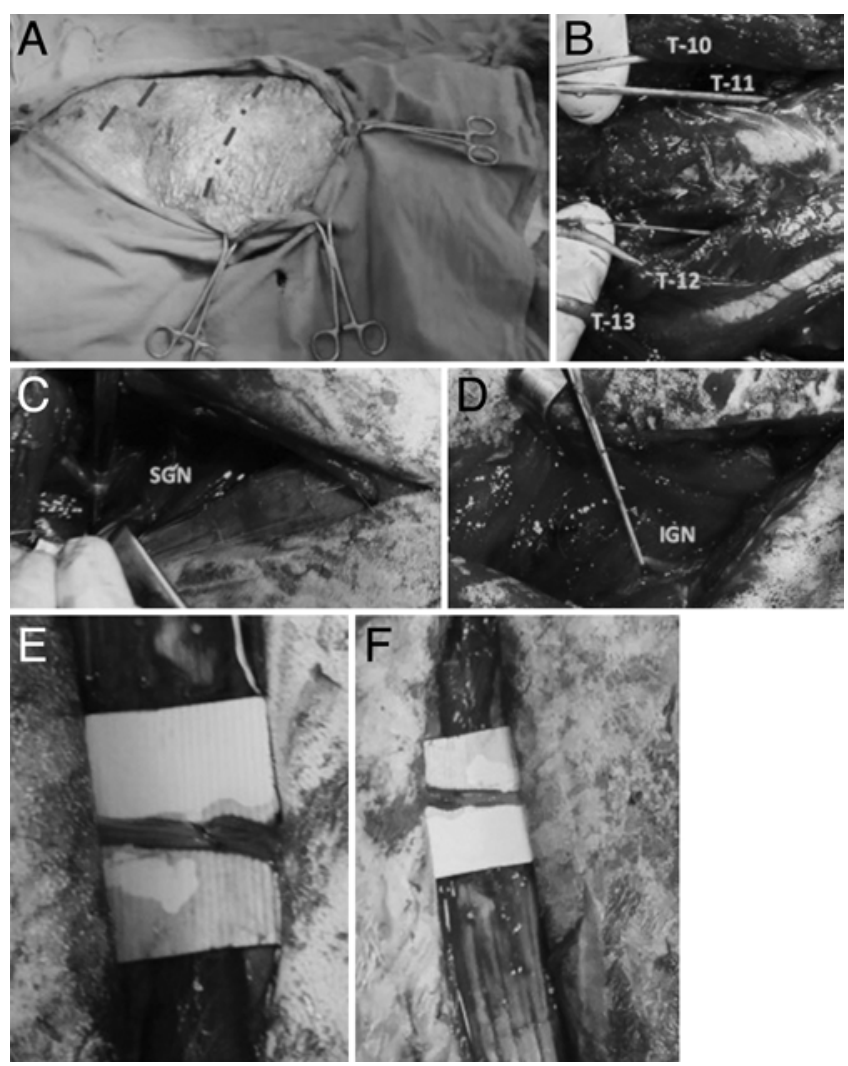

FIG. 3. Intercostal nerve transfer to the gluteal nerves in a dog. The dog was placed in a lateral position. A: The lateral thoracic incision and another 2 transgluteal incisions for superior gluteal nerve (SGN) and inferior gluteal nerve (IGN). B: Exploration of 10th (T-10), 11th (T-11), and 12th (T-12) intercostal nerves, and the subcostal nerve (T-13) C: Identification of SGN. D: Identification of IGN. E: The completed anastomosis after transfer of T-10 and T-11 to the SGN. F: The completed anastomosis after transfer of the 12th and 13th intercostal nerves to the IGN.

ogy skills. The muscles were examined using the criteria of the American Academy of Electrophysiological Medicine for needle EMG. An additional needle EMG of the quadriceps and glutei was performed after the procedure (monthly at each follow-up examination). ${ }^{11}$ Denervation was diagnosed if there was increased insertional activity $(>300 \mathrm{~m} / \mathrm{sec})$, electrophysiological evidence of positive sharp waves, fibrillation potentials, complex repetitive discharges, or other abnormal insertional or spontaneous potentials. Reinnervation was determined by the morphology and amplitude, duration, and firing pattern of the motor action potentials (MAPs). ${ }^{7}$

\section{Statistical Analysis}

Statistical analysis was performed with SPSS version 20 for Windows (IBM Corp.). Several variables were measured on a continuous scale. Descriptive statistics were summarized with frequencies or means \pm standard deviations. Preoperative and postoperative findings were compared by means of a Kruskal-Wallis $\mathrm{H}$ test, and then post hoc tests of multiple comparisons were calculated. A chi-square test was utilized for categorical data, unless any cell in the contingency table had a value of 5 or less, in 
which case Fisher's exact test was used. A p value $<0.05$ was considered to be statistically significant.

\section{Results \\ Cadaveric Study}

In the cadaveric model, the 9th, 10th, and 11th intercostal and the subcostal nerves were of sufficient length to be transferred in a tension-free manner to the superior and inferior gluteal nerves. The average length of available intercostal nerve required to reach the gluteal nerves in a tension-free manner was determined to be as follows: 9th, 10th, and 11th intercostal nerves $(16.8 \mathrm{~cm})$, and the subcostal nerve $(13.8 \mathrm{~cm})$. Similarly, the length of the ilioinguinal and iliohypogastric nerves from their emergence in the internal abdominal oblique muscle to just lateral to the midline ranged from $8 \mathrm{~cm}$ to $9.5 \mathrm{~cm}$, which is sufficient for transfer in a tension-free manner to the femoral nerve that is found about $6.5-8 \mathrm{~cm}$ from the ASIS.

Finally, to determine whether the intercostal nerves were appropriate for surgical anastomosis to the gluteal nerves, we measured the cross-sectional areas of each nerve. The mean cross-sectional area of the superior gluteal nerve was $4.3 \pm 0.169 \mathrm{~mm}^{2}$, that of the inferior gluteal nerve $4.9 \pm 0.154 \mathrm{~mm}^{2}$, and that of the intercostal nerves was $2.6 \pm 0.135 \mathrm{~mm}^{2}$. Therefore, 2 intercostal nerves matched the size of either the superior or the inferior gluteal nerve. For the ilioinguinal and iliohypogastric nerves, the cross-sectional area was about $2.78 \pm 0.32 \mathrm{~mm}^{2}$, while the cross-sectional area of the whole femoral nerve was $20.3 \pm 5.12 \mathrm{~mm}^{2}$; that of the central fascicle, which contains motor fibers to the vastus medialis and intermedius, was $5.7 \pm 0.59 \mathrm{~mm}^{2}$; and that of the lateral fascicle, which contains motor fibers to the vastus lateralis and rectus femoris, was $5.8 \pm 0.61 \mathrm{~mm}^{2}$. Thus, the ilioinguinal and iliohypogastric nerves each were approximately equivalent in cross-sectional area to half of the central or lateral fascicle, so a single ilioinguinal nerve was sutured to one of the fascicles and an iliohypogastric nerve to the other.

Regarding the internal topography of recipient and donor nerves, 4 distinct fascicles or groups of fascicles to the vastus medialis, vastus intermedius, vastus lateralis, and rectus femoris were observed and represented the distal nerve branches of the femoral nerve. Two smaller fascicles were seen inside the ilioinguinal nerve and also inside the iliohypogastric nerve. The superior gluteal nerve had 2 main fascicles; the cranial fascicle innervated the posterior regions of gluteus medius and terminated at the gluteus minimus, and the caudal fascicle innervated the anterior region of gluteus medius and terminated in tensor fascia lata muscle. The inferior gluteal nerve had 2 main groups of fascicles that supplied the gluteus maximus muscle. Each of the intercostal nerves had 1 smaller motor fascicle.

\section{Animal Study}

Clinically, in both groups of our animal model, a flaccid paralysis of the right abdominal wall was noted 3 months following surgery in all cases. The abdominal wall asymmetry did not improve during the 6 months of follow-up. In the NT group, the right lower limb flaccid paralysis improved at follow-up, and almost all animals regained quadriceps and gluteal muscle function (Table 1).

Most dogs in the NT group had grade 2 lameness with improved weight-bearing, while all dogs in the control group had grade 4 lameness with no weight-bearing at final follow-up (Table 1). There was no significant difference between the groups regarding the presence of pain at final follow-up $(\mathrm{p}=0.61)$.

The mean thigh circumference before surgery was significantly larger than that obtained at final follow-up in both groups $(\mathrm{p}<0.05)$. Comparison of values obtained in the 2 groups at final follow-up showed a significant improvement of the mean thigh circumference in the NT group (p < 0.05) (Fig. 4).

In 2 animals in the NT group, a pneumothorax was diagnosed and pleural drainage performed. One dog in each group experienced an early wound dehiscence, which was successfully treated by wound debridement and closure in both cases. A small pressure sore was seen in 1 dog in the control group because of the flaccid paralysis of the lower limb (Table 1).

Electrophysiologically, in the NT group, motor potentials were easily detected for all neurotized nerves (intercostal, subcostal, ilioinguinal, iliohypogastric, gluteal, and femoral nerves). There was a mild response of the femoral and gluteal nerves 6 weeks after the procedure, with a statistically significant reduction in amplitude in comparison to preoperative baseline assessment $(\mathrm{p}<0.001)$. However, this significant decrease of amplitude was reduced at the 3- and 6-month follow-up assessments. There was improvement of femoral and gluteal nerve amplitudes to about $92.8 \%$ (Fig. 5 left) and $96.1 \%$ (Fig. 5 right) of the preoperative baseline amplitude, with minor insignificant differences between baseline and 6-month values ( $\mathrm{p}>$ $0.05)$. In the control group, no motor potentials were detected along the femoral or gluteal nerves (Tables 2 and 3).

\section{Discussion}

The current study demonstrates the anatomical and technical feasibility of transferring intercostal to gluteal nerves and ilioinguinal and iliohypogastric nerves to femoral nerve in cadaveric and animal models. Harvesting and rerouting of donor nerves was performed easily in all cases. The intercostal nerves and the ilioinguinal and iliohypogastric nerves were long enough to reach the gluteal and femoral nerves, respectively. Therefore, coap-

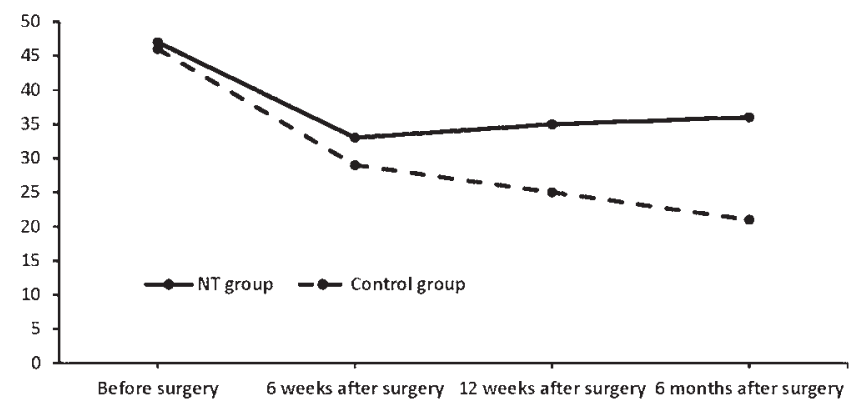

FIG. 4. Mean thigh circumference before and after surgery in NT and control groups. The y-axis shows thigh circumference in centimeters. 
TABLE 1. Clinical data and outcomes in the NT and control groups

\begin{tabular}{|c|c|c|c|c|c|c|c|c|c|}
\hline \multirow{2}{*}{$\begin{array}{l}\text { Dog } \\
\text { No. }\end{array}$} & \multirow{2}{*}{ Group } & \multirow{2}{*}{$\begin{array}{l}\text { Age } \\
\text { (mos) }\end{array}$} & \multirow[b]{2}{*}{ Type of Op } & \multirow[b]{2}{*}{ Complications } & \multicolumn{3}{|c|}{ Clinical Outcome } & \multirow[b]{2}{*}{ Pain } & \multirow{2}{*}{$\begin{array}{l}\text { Lameness } \\
\text { Score* }^{*}\end{array}$} \\
\hline & & & & & At 6 Wks & At 12 Wks & At 6 Mos & & \\
\hline 1 & NT & 12 & $\begin{array}{l}\text { Lumbar HS + } \\
\text { fem \& glut n. } \\
\text { neurot }\end{array}$ & Wound dehisc & $\begin{array}{l}\text { Compl LL mono- } \\
\text { plegia + Abd } \\
\text { wall paralysis }\end{array}$ & $\begin{array}{l}\text { Imprvmt of quad \& glut m. } \\
\text { FXN + Abd wall paraly- } \\
\text { sis w/ asymmetry }\end{array}$ & $\begin{array}{l}\text { Imprvmt of quad \& glut m. } \\
\text { FXN + Abd wall paraly- } \\
\text { sis w/ asymmetry }\end{array}$ & Yes & 3 \\
\hline 2 & NT & 14 & $\begin{array}{l}\text { Lumbar HS + } \\
\text { fem \& glut n. } \\
\text { neurot }\end{array}$ & None & $\begin{array}{l}\text { Compl LL mono- } \\
\text { plegia + Abd } \\
\text { wall paralysis }\end{array}$ & $\begin{array}{l}\text { Imprvmt of quad \& glut m. } \\
\text { FXN + Abd wall paraly- } \\
\text { sis w/ asymmetry }\end{array}$ & $\begin{array}{l}\text { Imprvmt of quad \& glut m. } \\
\text { FXN + Abd wall paraly- } \\
\text { sis w/ asymmetry }\end{array}$ & No & 2 \\
\hline 3 & NT & 18 & $\begin{array}{l}\text { Lumbar HS + } \\
\quad \text { fem \& glut n. } \\
\text { neurot }\end{array}$ & None & $\begin{array}{l}\text { Compl LL mono- } \\
\text { plegia + Abd } \\
\text { wall paralysis }\end{array}$ & $\begin{array}{l}\text { Imprvmt of quad \& glut m. } \\
\text { FXN + Abd wall paraly- } \\
\text { sis w/ asymmetry }\end{array}$ & $\begin{array}{l}\text { Imprvmt of quad \& glut m. } \\
\text { FXN + Abd wall paraly- } \\
\text { sis w/ asymmetry }\end{array}$ & No & 2 \\
\hline 4 & NT & 16 & $\begin{array}{l}\text { Lumbar HS + } \\
\text { fem \& glut n. } \\
\text { neurot }\end{array}$ & $\begin{array}{l}\text { Pneumotho- } \\
\quad \operatorname{rax}\end{array}$ & $\begin{array}{l}\text { Compl LL mono- } \\
\text { plegia + Abd } \\
\text { wall paralysis }\end{array}$ & $\begin{array}{l}\text { Imprvmt of quad \& glut m. } \\
\text { FXN + Abd wall paraly- } \\
\text { sis w/ asymmetry }\end{array}$ & $\begin{array}{l}\text { Imprvmt of quad \& glut m. } \\
\text { FXN + Abd wall paraly- } \\
\text { sis w/ asymmetry }\end{array}$ & Yes & 2 \\
\hline 5 & NT & 12 & $\begin{array}{l}\text { Lumbar HS + } \\
\quad \text { fem \& glut n. } \\
\text { neurot }\end{array}$ & None & $\begin{array}{l}\text { Compl LL mono- } \\
\text { plegia + Abd } \\
\text { wall paralysis }\end{array}$ & $\begin{array}{l}\text { Imprvmt of quad \& glut m. } \\
\text { FXN + Abd wall paraly- } \\
\text { sis w/ asymmetry }\end{array}$ & $\begin{array}{l}\text { Imprvmt of quad \& glut m. } \\
\text { FXN + Abd wall paraly- } \\
\text { sis w/ asymmetry }\end{array}$ & No & 1 \\
\hline 6 & NT & 18 & $\begin{array}{l}\text { Lumbar HS + } \\
\quad \text { fem \& glut n. } \\
\text { neurot }\end{array}$ & $\begin{array}{l}\text { Pneumotho- } \\
\quad \operatorname{rax}\end{array}$ & $\begin{array}{l}\text { Compl LL mono- } \\
\text { plegia + Abd } \\
\text { wall paralysis }\end{array}$ & $\begin{array}{l}\text { Imprvmt of quad \& glut m. } \\
\text { FXN + Abd wall paraly- } \\
\text { sis w/ asymmetry }\end{array}$ & $\begin{array}{l}\text { Imprvmt of quad \& glut m. } \\
\text { FXN + Abd wall paraly- } \\
\text { sis w/ asymmetry }\end{array}$ & Yes & 2 \\
\hline 7 & NT & 13 & $\begin{array}{l}\text { Lumbar HS + } \\
\quad \text { fem \& glut n. } \\
\text { neurot }\end{array}$ & None & $\begin{array}{l}\text { Compl LL mono- } \\
\text { plegia + Abd } \\
\text { wall paralysis }\end{array}$ & $\begin{array}{l}\text { Imprvmt of quad \& glut m. } \\
\text { FXN + Abd wall paraly- } \\
\text { sis w/ asymmetry }\end{array}$ & $\begin{array}{l}\text { Imprvmt of quad \& glut m. } \\
\text { FXN + Abd wall paraly- } \\
\text { sis w/ asymmetry }\end{array}$ & No & 2 \\
\hline 8 & NT & 15 & $\begin{array}{l}\text { Lumbar HS + } \\
\quad \text { fem \& glut n. } \\
\text { neurot }\end{array}$ & None & $\begin{array}{l}\text { Compl LL mono- } \\
\text { plegia + Abd } \\
\text { wall paralysis }\end{array}$ & $\begin{array}{l}\text { Imprvmt of quad \& glut m. } \\
\text { FXN + Abd wall paraly- } \\
\text { sis w/ asymmetry }\end{array}$ & $\begin{array}{l}\text { Imprvmt of quad \& glut m. } \\
\text { FXN + Abd wall paraly- } \\
\text { sis w/ asymmetry }\end{array}$ & No & 2 \\
\hline 9 & NT & 17 & $\begin{array}{l}\text { Lumbar HS + } \\
\quad \text { fem \& glut n. } \\
\text { neurot }\end{array}$ & None & $\begin{array}{l}\text { Compl LL mono- } \\
\text { plegia + Abd } \\
\text { wall paralysis }\end{array}$ & $\begin{array}{l}\text { Imprvmt of quad \& glut m. } \\
\text { FXN + Abd wall paraly- } \\
\text { sis w/ asymmetry }\end{array}$ & $\begin{array}{l}\text { Imprvmt of quad \& glut m. } \\
\text { FXN + Abd wall paraly- } \\
\text { sis w/ asymmetry }\end{array}$ & No & 2 \\
\hline 10 & NT & 14 & $\begin{array}{l}\text { Lumbar HS + } \\
\quad \text { fem \& glut n. } \\
\text { neurot }\end{array}$ & None & $\begin{array}{l}\text { Compl LL mono- } \\
\text { plegia + Abd } \\
\text { wall paralysis }\end{array}$ & $\begin{array}{l}\text { Imprvmt of quad \& glut m. } \\
\text { FXN + Abd wall paraly- } \\
\text { sis w/ asymmetry }\end{array}$ & $\begin{array}{l}\text { Imprvmt of quad \& glut m. } \\
\text { FXN + Abd wall paraly- } \\
\text { sis w/ asymmetry }\end{array}$ & No & 2 \\
\hline 11 & Ctrl & 18 & Lumbar HS & None & $\begin{array}{l}\text { Compl LL mono- } \\
\text { plegia + Abd } \\
\text { wall paralysis }\end{array}$ & $\begin{array}{l}\text { Compl LL monoplegia + } \\
\text { Abd wall paralysis w/ } \\
\text { asymmetry }\end{array}$ & $\begin{array}{l}\text { Compl LL monoplegia + } \\
\text { Abd wall paralysis w/ } \\
\text { asymmetry }\end{array}$ & No & 4 \\
\hline 12 & Ctrl & 18 & Lumbar HS & None & $\begin{array}{l}\text { Compl LL mono- } \\
\text { plegia + Abd } \\
\text { wall paralysis }\end{array}$ & $\begin{array}{l}\text { Compl LL monoplegia + } \\
\text { Abd wall paralysis w/ } \\
\text { asymmetry }\end{array}$ & $\begin{array}{l}\text { Compl LL monoplegia + } \\
\text { Abd wall paralysis w/ } \\
\text { asymmetry }\end{array}$ & No & 4 \\
\hline 13 & Ctrl & 16 & Lumbar HS & None & $\begin{array}{l}\text { Compl LL mono- } \\
\text { plegia + Abd } \\
\text { wall paralysis }\end{array}$ & $\begin{array}{l}\text { Compl LL monoplegia + } \\
\text { Abd wall paralysis w/ } \\
\text { asymmetry }\end{array}$ & $\begin{array}{l}\text { Compl LL monoplegia + } \\
\text { Abd wall paralysis w/ } \\
\text { asymmetry }\end{array}$ & No & 4 \\
\hline 14 & Ctrl & 12 & Lumbar HS & Wound dehisc & $\begin{array}{l}\text { Compl LL mono- } \\
\text { plegia + Abd } \\
\text { wall paralysis }\end{array}$ & $\begin{array}{l}\text { Compl LL monoplegia + } \\
\text { Abd wall paralysis w/ } \\
\text { asymmetry }\end{array}$ & $\begin{array}{l}\text { Compl LL monoplegia + } \\
\text { Abd wall paralysis w/ } \\
\text { asymmetry }\end{array}$ & Yes & 4 \\
\hline 15 & Ctrl & 17 & Lumbar HS & None & $\begin{array}{l}\text { Compl LL mono- } \\
\text { plegia + Abd } \\
\text { wall paralysis }\end{array}$ & $\begin{array}{l}\text { Compl LL monoplegia + } \\
\text { Abd wall paralysis w/ } \\
\text { asymmetry }\end{array}$ & $\begin{array}{l}\text { Compl LL monoplegia + } \\
\text { Abd wall paralysis w/ } \\
\text { asymmetry }\end{array}$ & No & 4 \\
\hline 16 & Ctrl & 12 & Lumbar HS & None & $\begin{array}{l}\text { Compl LL mono- } \\
\text { plegia + Abd } \\
\text { wall paralysis }\end{array}$ & $\begin{array}{l}\text { Compl LL monoplegia + } \\
\text { Abd wall paralysis w/ } \\
\text { asymmetry }\end{array}$ & $\begin{array}{l}\text { Compl LL monoplegia + } \\
\text { Abd wall paralysis w/ } \\
\text { asymmetry }\end{array}$ & No & 4 \\
\hline 17 & Ctrl & 14 & Lumbar HS & $\begin{array}{l}\text { LL pressure } \\
\text { sores }\end{array}$ & $\begin{array}{l}\text { Compl LL mono- } \\
\text { plegia + Abd } \\
\text { wall paralysis }\end{array}$ & $\begin{array}{l}\text { Compl LL monoplegia + } \\
\text { Abd wall paralysis w/ } \\
\text { asymmetry }\end{array}$ & $\begin{array}{l}\text { Compl LL monoplegia + } \\
\text { Abd wall paralysis w/ } \\
\text { asymmetry }\end{array}$ & Yes & 4 \\
\hline
\end{tabular}


Toreih et al.

» CONTINUED FROM PAGE 273

TABLE 1. Clinical data and outcomes in the NT and control groups

\begin{tabular}{|c|c|c|c|c|c|c|c|c|c|}
\hline \multirow{2}{*}{$\begin{array}{l}\text { Dog } \\
\text { No. }\end{array}$} & \multirow[b]{2}{*}{ Group } & \multirow{2}{*}{$\begin{array}{l}\text { Age } \\
\text { (mos) }\end{array}$} & \multirow[b]{2}{*}{ Type of Op } & \multirow[b]{2}{*}{ Complications } & \multicolumn{3}{|c|}{ Clinical Outcome } & \multirow[b]{2}{*}{ Pain } & \multirow{2}{*}{$\begin{array}{c}\text { Lameness } \\
\text { Score }^{*}\end{array}$} \\
\hline & & & & & At 6 Wks & At 12 Wks & At 6 Mos & & \\
\hline 18 & Ctrl & 15 & Lumbar HS & None & $\begin{array}{l}\text { Compl LL mono- } \\
\text { plegia + Abd } \\
\text { wall paralysis }\end{array}$ & $\begin{array}{l}\text { Compl LL monoplegia + } \\
\text { Abd wall paralysis w/ } \\
\text { asymmetry }\end{array}$ & $\begin{array}{l}\text { Compl LL monoplegia + } \\
\text { Abd wall paralysis w/ } \\
\text { asymmetry }\end{array}$ & No & 4 \\
\hline 19 & Ctrl & 13 & Lumbar HS & None & $\begin{array}{l}\text { Compl LL mono- } \\
\text { plegia + Abd } \\
\text { wall paralysis }\end{array}$ & $\begin{array}{l}\text { Compl LL monoplegia + } \\
\text { Abd wall paralysis w/ } \\
\text { asymmetry }\end{array}$ & $\begin{array}{l}\text { Compl LL monoplegia + } \\
\text { Abd wall paralysis w/ } \\
\text { asymmetry }\end{array}$ & No & 4 \\
\hline 20 & Ctrl & 13 & Lumbar HS & None & $\begin{array}{l}\text { Compl LL mono- } \\
\text { plegia + Abd } \\
\text { wall paralysis }\end{array}$ & $\begin{array}{l}\text { Comple LL monoplegia + } \\
\text { Abd wall paralysis w/ } \\
\text { asymmetry }\end{array}$ & $\begin{array}{l}\text { Compl LL monoplegia + } \\
\text { Abd wall paralysis w/ } \\
\text { asymmetry }\end{array}$ & No & 4 \\
\hline
\end{tabular}

Abd = abdominal; compl = complete; ctrl = control; dehisc = dehiscence; fem = femoral; FXN = function; glut = gluteal; $\mathrm{HS}=$ hemisection; imprvmt = improvement; LL = lower limb; $\mathrm{m}$. = muscle; $\mathrm{n}$. = nerve; neurot = neurotization; quad = quadriceps.

* Lameness was scored on a scale of 0 to 4.

tation could be performed in a tension-free manner. Additionally, the cross-sectional areas of 2 intercostal nerves were sufficiently equivalent to that of either the superior or the inferior gluteal nerve, and the cross-sectional areas of the ilioinguinal and iliohypogastric nerves were equivalent to half the cross-sectional areas of either the central or the lateral fascicle of the femoral nerve. Accordingly, it is expected that nearly half the quadriceps function could be restored. Regarding the length of donor nerves and the fascicle count of both donor and recipient nerves, our findings were similar to those reported by various anatomical feasibility studies that investigated the internal topography of the nerves. ${ }^{14,15,18,31-34}$

Electrophysiological recording of motor potentials in all stimulated nerves was easily performed before and after the neurotization procedure. In all dogs, the ability of motor axons to regenerate through the neurotization area down to the motor endplates was proved. The clinical significance of the muscle strength recovery was demonstrated in the restoration of some hip and knee functions. This was emphasized by the insignificant difference of the amplitude and latency of the recipient nerves (gluteal and femoral nerves) between preoperative baseline readings and those recorded at final follow-up. Although the regaining of motor function in our animal model could be attributed to the natural recovery of intrinsic spinal cord function, the persistence of abdominal wall paralysis is highly suggestive of a contribution from only the transferred nerves. Because nerve transfers were performed acutely (i.e., at the same time of denervation) in order to obtain the best clinical outcomes by minimizing the denervation time, our results concerning the poor regeneration of axons in chronically denervated muscles should be investigated.

Animal studies of SCI have been performed with reported recovery of lower limb function and sometimes ambulation in dogs and rats. ${ }^{19,40}$ Human cadaveric studies of SCI have similarly focused on nerve transfer to the lumbosacral plexus or insertion directly into the spinal cord through a dural window. Some studies reported that the 9th, 10th, and 11th intercostal nerves are of sufficient length to be readily transferred to the lumbar nerve roots
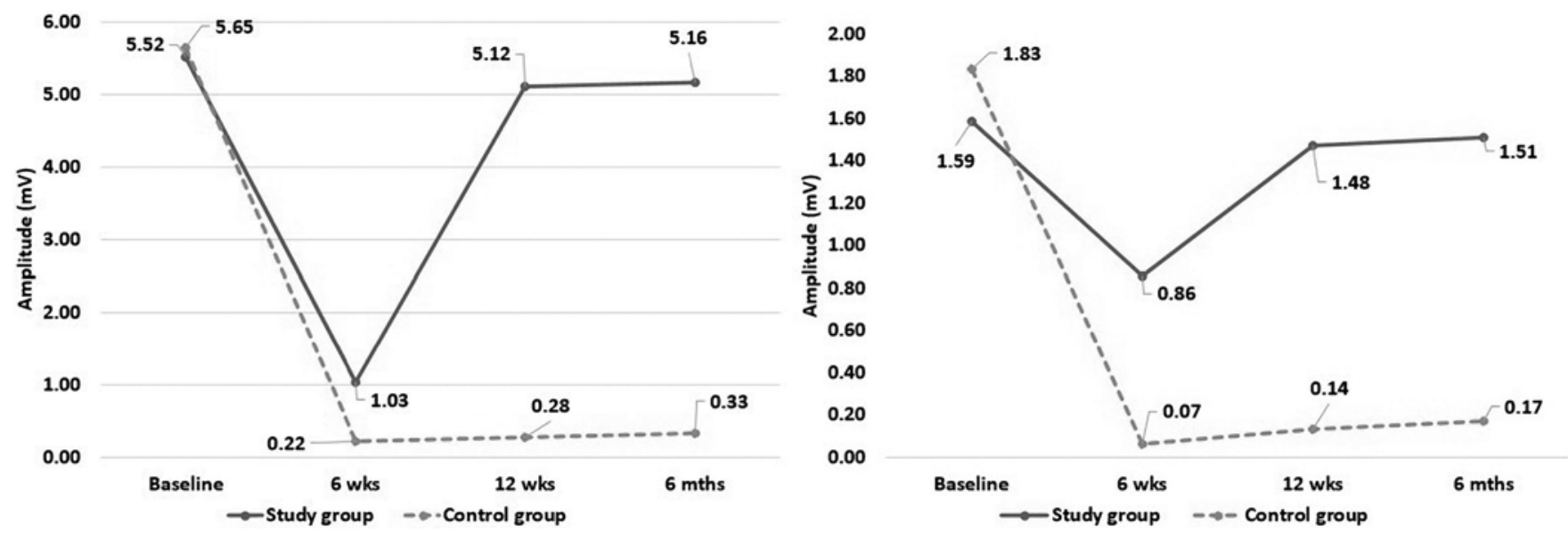

FIG. 5. The amplitude of the MAPs in the study and control groups at baseline and the 6-week, 12-week, and 6-month follow-up assessments of the femoral nerve (left) and gluteal nerves (right). 
TABLE 2. Femoral nerve MAP latency, amplitude, and duration in the NT and control groups at baseline, 6 and 12 weeks, and 6 months

\begin{tabular}{|c|c|c|c|c|c|c|c|c|}
\hline \multirow[b]{2}{*}{ Dog No. } & \multicolumn{4}{|c|}{ NT Group } & \multicolumn{4}{|c|}{ Control Group } \\
\hline & Baseline & $6 \mathrm{Wks}$ & 12 Wks & 6 Mos & Baseline & $6 \mathrm{Wks}$ & 12 Wks & 6 Mos \\
\hline \multicolumn{9}{|c|}{ Latency (msec) } \\
\hline 1 & 3.52 & 3.23 & 4.19 & 3.01 & 2.76 & 5.48 & 5.77 & 4.39 \\
\hline 2 & 3.74 & 4.02 & 3.21 & 3.54 & 3.99 & 6.71 & 5.87 & 6.15 \\
\hline 3 & 3.19 & 3.11 & 3.47 & 2.89 & 3.71 & - & - & - \\
\hline 4 & 3.62 & 2.41 & 3.66 & 3.57 & 2.97 & - & - & - \\
\hline 5 & 3.67 & 2.36 & 3.72 & 3.91 & 3.18 & 4.38 & 5.76 & 4.93 \\
\hline 6 & 3.17 & 3.12 & 3.51 & 4.03 & 2.86 & - & - & - \\
\hline 7 & 3.91 & 2.19 & 3.43 & 4.38 & 3.82 & - & - & - \\
\hline 8 & 3.98 & 3.05 & 4.25 & 3.28 & 3.16 & - & - & - \\
\hline 9 & 3.23 & 3.15 & 4.17 & 2.61 & 3.06 & 5.67 & 5.98 & 5.31 \\
\hline 10 & 3.21 & 2.04 & 3.01 & 3.13 & 3.59 & - & - & - \\
\hline \multicolumn{9}{|c|}{ Amplitude (mV) } \\
\hline 1 & 5.25 & 0.51 & 4.89 & 4.91 & 6.63 & 0.51 & 0.49 & 0.58 \\
\hline 2 & 5.12 & 0.92 & 4.98 & 5.00 & 6.21 & 0.03 & 0.12 & 0.09 \\
\hline 3 & 4.39 & 1.32 & 4.08 & 4.12 & 5.73 & - & - & - \\
\hline 4 & 4.48 & 1.67 & 4.26 & 4.31 & 5.54 & - & - & - \\
\hline 5 & 7.23 & 2.14 & 5.97 & 5.99 & 5.39 & 0.01 & 0.04 & 0.08 \\
\hline 6 & 6.36 & 1.01 & 6.15 & 6.21 & 7.15 & - & - & - \\
\hline 7 & 7.04 & 0.84 & 6.49 & 6.57 & 5.25 & - & - & - \\
\hline 8 & 6.19 & 0.68 & 5.62 & 5.71 & 5.47 & - & - & - \\
\hline 9 & 4.59 & 0.63 & 4.28 & 4.32 & 4.72 & 0.32 & 0.38 & 0.46 \\
\hline 10 & 4.43 & 0.58 & 4.32 & 4.38 & 5.38 & - & - & - \\
\hline \multicolumn{9}{|c|}{ Duration (msec) } \\
\hline 1 & 5.02 & 3.31 & 5.37 & 7.35 & 6.27 & 7.68 & 7.89 & 6.39 \\
\hline 2 & 5.21 & 3.23 & 6.94 & 6.55 & 6.51 & 5.46 & 5.97 & 5.58 \\
\hline 3 & 4.70 & 3.48 & 5.74 & 5.29 & 5.28 & - & - & - \\
\hline 4 & 4.44 & 2.98 & 6.82 & 5.97 & 5.76 & - & - & - \\
\hline 5 & 5.11 & 3.29 & 6.88 & 6.34 & 4.84 & 5.58 & 6.17 & 5.12 \\
\hline 6 & 5.08 & 4.01 & 7.32 & 7.36 & 4.79 & - & - & - \\
\hline 7 & 6.35 & 3.25 & 5.84 & 5.62 & 5.37 & - & - & - \\
\hline 8 & 5.14 & 3.31 & 6.79 & 5.36 & 5.62 & - & - & - \\
\hline 9 & 6.05 & 2.47 & 4.38 & 6.82 & 5.21 & 5.95 & 5.83 & 6.53 \\
\hline 10 & 4.46 & 3.16 & 5.87 & 5.61 & 4.53 & - & - & - \\
\hline
\end{tabular}

in both infant and adult human cadavers, ${ }^{20,34}$ and another study showed that intercostal nerves are acceptable donors for transfer to the sacral nerve roots. ${ }^{36}$ Haque et al. transferred the intercostal nerves and sequentially inserted them $4 \mathrm{~mm}$ deep into the conus medullaris through a dural opening. 15

SCI bypass models that transfer peripheral nerves to spinal roots or the spinal cord have one very important limitation: transferred nerve fibers must grow into distal spinal roots and through the length of peripheral nerves to reach their targets and restore function. The regeneration distance between lumbar nerve roots and distal targets (lower leg muscles) is very long, and hypothetically would require many years for reinnervation. This lengthy time may preclude useful motor recovery, as substantial motor endplate atrophy and irreversible muscle fibrosis can occur in that time frame. ${ }^{28}$ The novel distal nerve transfers proposed in our study, however, allow for more prompt motor reinnervation of distal motor endplate in the target muscles by decreasing the regeneration gap. ${ }^{6}$ It was emphasized that use of motor donors as close as possible to the recipient motor endplates minimizes the loss of recipient motor units and allows appropriate postoperative physical therapy. ${ }^{5}$

Early case studies and small series have described accounts of variable functional recovery, but in general are limited by minimal follow-up and inconsistent results. ${ }^{8,13,25}$ Moderate recovery of lower limb motor function (Medical Research Council [MRC] grades 1-3) was reported in 5 of 21 patients following intercostal transfer to lumbosacral nerve roots. ${ }^{10}$ In one promising clinical series, 18 of 23 patients were reported to have regained the ability to step forward and were eventually able to walk with an ambula- 
TABLE 3. Gluteal nerve MAP latency, amplitude, and duration in the NT and control groups at baseline, 6 and 12 weeks, and 6 months

\begin{tabular}{|c|c|c|c|c|c|c|c|c|}
\hline \multirow[b]{2}{*}{ Dog No. } & \multicolumn{4}{|c|}{ NT Group } & \multicolumn{4}{|c|}{ Control Group } \\
\hline & Baseline & $6 \mathrm{Wks}$ & 12 Wks & 6 Mos & Baseline & $6 \mathrm{Wks}$ & $12 \mathrm{Wks}$ & $6 \mathrm{Mos}$ \\
\hline \multicolumn{9}{|c|}{ Latency (msec) } \\
\hline 1 & 2.21 & 3.21 & 3.06 & 2.34 & 3.03 & - & - & - \\
\hline 2 & 2.13 & 2.98 & 3.02 & 2.52 & 2.41 & - & - & - \\
\hline 3 & 2.17 & 3.52 & 3.42 & 3.84 & 2.20 & - & - & - \\
\hline 4 & 2.18 & 3.89 & 3.21 & 3.08 & 2.31 & - & - & - \\
\hline 5 & 2.16 & 3.81 & 3.32 & 2.58 & 2.36 & 6.38 & 6.62 & 7.21 \\
\hline 6 & 2.24 & 3.75 & 3.18 & 2.41 & 3.21 & - & - & - \\
\hline 7 & 2.27 & 3.56 & 3.32 & 2.65 & 2.11 & 7.92 & 6.89 & 7.06 \\
\hline 8 & 3.00 & 3.27 & 3.13 & 3.29 & 2.67 & - & - & - \\
\hline 9 & 2.21 & 3.48 & 3.36 & 2.53 & 2.62 & - & - & - \\
\hline 10 & 2.25 & 2.99 & 2.72 & 2.84 & 2.48 & - & - & - \\
\hline \multicolumn{9}{|c|}{ Amplitude (mV) } \\
\hline 1 & 1.58 & 0.54 & 1.45 & 1.47 & 2.26 & - & - & - \\
\hline 2 & 1.27 & 0.88 & 1.19 & 1.21 & 2.31 & - & - & - \\
\hline 3 & 1.46 & 0.73 & 1.34 & 1.38 & 1.58 & - & - & - \\
\hline 4 & 1.51 & 0.94 & 1.38 & 1.45 & 1.93 & - & - & - \\
\hline 5 & 1.47 & 0.71 & 1.28 & 1.32 & 1.49 & 0.03 & 0.09 & 0.12 \\
\hline 6 & 2.00 & 1.33 & 1.95 & 1.99 & 2.14 & - & - & - \\
\hline 7 & 2.17 & 0.97 & 1.98 & 2.01 & 1.74 & 0.10 & 0.18 & 0.22 \\
\hline 8 & 1.49 & 0.58 & 1.33 & 1.37 & 1.53 & - & - & - \\
\hline 9 & 1.33 & 0.92 & 1.25 & 1.28 & 1.72 & - & - & - \\
\hline 10 & 1.25 & 0.84 & 1.19 & 1.22 & 2.16 & - & - & - \\
\hline \multicolumn{9}{|c|}{ Duration (msec) } \\
\hline 1 & 3.89 & 4.34 & 4.30 & 4.42 & 4.34 & - & - & - \\
\hline 2 & 4.24 & 4.67 & 4.87 & 5.17 & 4.02 & - & - & - \\
\hline 3 & 3.52 & 3.83 & 3.97 & 4.28 & 3.78 & - & - & - \\
\hline 4 & 3.48 & 3.78 & 4.99 & 5.22 & 3.51 & - & - & - \\
\hline 5 & 3.21 & 4.76 & 4.95 & 5.24 & 2.99 & 5.53 & 5.84 & 5.62 \\
\hline 6 & 2.72 & 3.89 & 4.81 & 4.97 & 3.82 & - & - & - \\
\hline 7 & 3.28 & 4.77 & 5.34 & 5.52 & 3.14 & 6.73 & 6.57 & 7.04 \\
\hline 8 & 2.98 & 4.85 & 4.96 & 5.11 & 3.25 & - & - & - \\
\hline 9 & 3.19 & 4.92 & 5.62 & 5.71 & 2.53 & - & - & - \\
\hline 10 & 2.85 & 5.24 & 5.86 & 5.94 & 2.71 & - & - & - \\
\hline
\end{tabular}

tory assistive device following transfer of 2 or 4 intercostal nerves to various lumbar nerve roots. ${ }^{39}$

General anesthesia was induced using various agents such as enflurane, halothane, neuroleptics, nitrous oxide, and propofol. $12,17,32,35,38$ But in our study, each dog was premedicated with intramuscular injection of chlorpromazine hydrochloride and general anesthesia was induced by intravenous administration of thiopental sodium $2.5 \%$ solution until the disappearance of all main reflexes. This technique is popular in our institution.

Regarding the surgical technique, we performed such nerve transfers without technical difficulties because of the size of the model and the harvesting technique. The harvesting technique was previously performed in some human cadaveric studies., ${ }^{9,31,32}$

The quadriceps muscle strength during electrophysi- ological testing is directly proportional to the degree of muscle wasting in humans. ${ }^{16}$ Although it is difficult to measure motor power in dogs compared to humans, improvements in thigh circumference can be used as an indicator of improvement of quadriceps strength. ${ }^{22}$ Thigh circumference measurement is easy, reliable, and commonly performed in practice for the detection of muscle mass in dogs. ${ }^{37}$ Thigh circumference improved in all dogs of the NT group. Similarly, lameness scores and willingness to bear weight on the affected limb significantly improved for all dogs of the NT group at final follow-up compared to the control group.

Dogs frequently remain lame for several months after surgery because of lower limb muscle paralysis, until reinnervation ensues. Therefore, lameness scores are not suitable as early indicators of improvement. However, range 
of motion, thigh circumference, and motor power grade provide reliable tools for functional assessment in humans. ${ }^{21,22,30}$

Our study had a relatively low incidence of complications. Pneumothorax occurred in 2 of $10 \mathrm{dogs}$ in the NT group as an iatrogenic complication during exploration and identification of the intercostal nerves. It was treated successfully by pleural drainage in both cases.

Although some would argue that the utilization of only cadaveric and animal models rather than performing surgeries in human patients is a limitation of the study, the anatomical and technical feasibility must be tested before these surgical procedures are performed in humans. Furthermore, the surgical approach in the clinical setting would probably not be substantially different from that in cadaver dissections, unless patients had suffered substantial intra-abdominal, retroperitoneal, or lower thoracic adhesions because of previous surgical procedures.

The inability to determine axon number per cut nerve sections in the cadaver model could also be cited as a limitation of this study. It can be attributed to the type of applied fixation methods for the cadavers and the long period between fixation and dissection, as these cadavers were preserved for educational use only. Nevertheless, we carried out such nerve transfers in the animal model without technical difficulties because of the considerable model size. The harvesting technique was also reproducible.

Despite the small number of animals, follow-up evaluation at 6 months postoperatively was completed in all animals. Upcoming studies on larger groups of animals are recommended. Supplementary studies utilizing our novel technique are still being performed at our institution.

\section{Conclusions}

Intercostal, ilioinguinal, and iliohypogastric nerves are suitable donors for transfer to the gluteal and femoral nerves after SCI to restore some hip and knee motor functions with detectable levels of activity in recipient nerves and their target musculature. Although other studies have investigated nerve transfers at the spine level, we believe that our approach near the target organ may afford a more robust intervention. This procedure would avoid the long regeneration distance from the spinal roots to the target motor endplates.

\section{References}

1. Augutis M, Levi R: Pediatric spinal cord injury in Sweden: incidence, etiology and outcome. Spinal Cord 41:328-336, 2003

2. Bickenbach J, Officer A, Shakespeare T, von Groote P (eds): International Perspectives on Spinal Cord Injury. Geneva: World Health Organization, 2013

3. Bos JC, Stoeckart R, Klooswijk AI, van Linge B, Bahadoer $\mathrm{R}$ : The surgical anatomy of the superior gluteal nerve and anatomical radiologic bases of the direct lateral approach to the hip. Surg Radiol Anat 16:253-258, 1994

4. Brown JM, Barbe MF, Albo ME, Lai HH, Ruggieri MR Sr: Anatomical feasibility of performing intercostal and ilioinguinal nerve to pelvic nerve transfer: a possible technique to restore lower urinary tract innervation. J Neurosurg Spine 17:357-362, 2012

5. Brown JM, Mackinnon SE: Nerve transfers in the forearm and hand. Hand Clin 24:319-340, v, 2008
6. Brown JM, Shah MN, Mackinnon SE: Distal nerve transfers: a biology-based rationale. Neurosurg Focus 26(2):E12, 2009

7. Brown WF, Bolton CF: Clinical Electromyography. Boston: Butterworths, 1987

8. Carlsson CA, Sundin T: Reconstruction of afferent and efferent nervous pathways to the urinary bladder in two paraplegic patients. Spine (Phila Pa 1976) 5:37-41, 1980

9. Court C, Vialle R, Lepeintre JF, Tadié M: The thoracoabdominal intercostal nerves: an anatomical study for their use in neurotization. Surg Radiol Anat 27:8-14, 2005

10. Dai KR, Yu CT, Wu RS, Zhang XF, Yuan JX, Sun YH: Intercostal-lumbar-spinal nerve anastomoses for cord transection. A preliminary investigation. J Reconstr Microsurg 1:223-226, 1985

11. Daube JR: AAEM minimonograph \#11: Needle examination in clinical electromyography. Muscle Nerve 14:685-700, 1991

12. Deletis V, Kiprovski K, Morota N: The influence of halothane, enflurane, and isoflurane on motor evoked potentials. Neurosurgery 33:173-174, 1993

13. Epstein F, Spielholz N, Battista A, McCarthy J: Delayed cauda equina reconstruction in meningomyelocele: preliminary report. Neurosurgery 6:540-541, 1980

14. Gustafson KJ, Pinault GC, Neville JJ, Syed I, Davis JA Jr, Jean-Claude J, et al: Fascicular anatomy of human femoral nerve: implications for neural prostheses using nerve cuff electrodes. J Rehabil Res Dev 46:973-984, 2009

15. Haque RM, Malone HR, Bauknight MW, Kellner MA, Ogden AT, Martin JH, et al: Spinal cord bypass surgery with intercostal and spinal accessory nerves: an anatomical feasibility study in human cadavers. J Neurosurg Spine 16:178-186, 2012

16. Järvelä T, Kannus P, Latvala K, Järvinen M: Simple measurements in assessing muscle performance after an ACL reconstruction. Int J Sports Med 23:196-201, 2002

17. Kalkman CJ, Been HD, Ongerboer de Visser BW: Intraoperative monitoring of spinal cord function. A review. Acta Orthop Scand 64:114-123, 1993

18. Klaassen Z, Marshall E, Tubbs RS, Louis RG Jr, Wartmann CT, Loukas M: Anatomy of the ilioinguinal and iliohypogastric nerves with observations of their spinal nerve contributions. Clin Anat 24:454-461, 2011

19. Liu S, Peulve P, Jin O, Boisset N, Tiollier J, Said G, et al: Axonal regrowth through collagen tubes bridging the spinal cord to nerve roots. J Neurosci Res 49:425-432, 1997

20. Malik HG, Buhr AJ: Intercostal nerve transfer to lumbar nerve roots. Part I: development of an animal model and cadaver studies. Spine (Phila Pa 1976) 4:410-415, 1979

21. Marsolais GS, McLean S, Derrick T, Conzemius MG: Kinematic analysis of the hind limb during swimming and walking in healthy dogs and dogs with surgically corrected cranial cruciate ligament rupture. J Am Vet Med Assoc 222:739-743, 2003

22. Monk ML, Preston CA, McGowan CM: Effects of early intensive postoperative physiotherapy on limb function after tibial plateau leveling osteotomy in dogs with deficiency of the cranial cruciate ligament. Am J Vet Res 67:529-536, 2006

23. Mostafa AA, Griffon DJ, Thomas MW, Constable PD: Morphometric characteristics of the pelvic limbs of Labrador Retrievers with and without cranial cruciate ligament deficiency. Am J Vet Res 70:498-507, 2009

24. Oppenheim JS, Spitzer DE, Winfree CJ: Spinal cord bypass surgery using peripheral nerve transfers: review of translational studies and a case report on its use following complete spinal cord injury in a human. Experimental article. Neurosurg Focus 26(2):E6, 2009

25. Patil A: Intercostal nerves to spinal nerve roots anastomosis (spinal cord bypass) and Harrington rod fusion in traumatic paraplegia - technical note. Acta Neurochir (Wien) 57:299_ 303, 1981 
26. Pieber K, Herceg M, Paternostro-Sluga T, Schuhfried O: Optimizing stimulation parameters in functional electrical stimulation of denervated muscles: a cross-sectional study. J Neuroeng Rehabil 12:51, 2015

27. Puisto V, Kääriäinen S, Impinen A, Parkkila T, Vartiainen E, Jalanko T, et al: Incidence of spinal and spinal cord injuries and their surgical treatment in children and adolescents: a population-based study. Spine (Phila Pa 1976) 35:104-107, 2010

28. Scelsi R, Marchetti C, Poggi P, Lotta S, Lommi G: Muscle fiber type morphology and distribution in paraplegic patients with traumatic cord lesion. Histochemical and ultrastructural aspects of rectus femoris muscle. Acta Neuropathol 57:243248, 1982

29. Schneider CA, Rasband WS, Eliceiri KW: NIH Image to Image J: 25 years of image analysis. Nat Methods 9:671-675, 2012

30. Tyler TF, McHugh MP, Gleim GW, Nicholas SJ: The effect of immediate weightbearing after anterior cruciate ligament reconstruction. Clin Orthop Relat Res (357):141-148, 1998

31. Vialle R, Court C, Harding I, Lepeintre JF, Khouri N, Tadié M: Multiple lumbar plexus neurotizations of the ninth, tenth, and eleventh intercostal nerves. Clin Anat 19:51-58, 2006

32. Vialle R, Court C, Harding I, Lepeintre JF, Khouri N, Tadié M: Retraction for "Multiple lumbar plexus neurotizations of the ninth, tenth, and eleventh intercostal nerves," Clinical Anatomy 19:51-58, 2006. Clin Anat 21:754, 2008

33. Vialle R, Lacroix C, Harding I, Loureiro MC, Tadié M: Motor and sensitive axonal regrowth after multiple intercostolumbar neurotizations in a sheep model. Spinal Cord 48:367-374, 2010

34. Vialle R, Lepeintre JF, Court C, Loureiro MC, Lacroix C, Tadié M: Anatomical feasibility of using the ninth, 10th, and 11th intercostal nerves for the treatment of neurological deficits after damage to the spinal cord. J Neurosurg Spine 4:225-232, 2006

35. Vialle R, Lozeron P, Loureiro MC, Tadié M: Multiple lumbar roots neurotizations with the lower intercostal nerves. Preliminary clinical and electrophysiological results in a sheep model. J Surg Res 149:199-205, 2008

36. Vorstman B, Schlossberg S, Landy H, Kass L: Nerve crossover techniques for urinary bladder reinnervation: animal and human cadaver studies. J Urol 137:1043-1047, 1987
37. Weiss LW, Coney HD, Clark FC: Gross measures of exerciseinduced muscular hypertrophy. J Orthop Sports Phys Ther 30:143-148, 2000

38. Zentner J, Albrecht T, Heuser D: Influence of halothane, enflurane, and isoflurane on motor evoked potentials. Neurosurgery 31:298-305, 1992

39. Zhang S, Johnston L, Zhang Z, Ma Y, Hu Y, Wang J, et al: Restoration of stepping-forward and ambulatory function in patients with paraplegia: rerouting of vascularized intercostal nerves to lumbar nerve roots using selected interfascicular anastomosis. Surg Technol Int 11:244-248, 2003

40. Zhao S, Beuerman RW, Kline DG: Neurotization of motor nerves innervating the lower extremity by utilizing the lower intercostal nerves. J Reconstr Microsurg 13:39-45, 1997

\section{Disclosures}

The authors report no conflict of interest concerning the materials or methods used in this study or the findings specified in this paper.

\section{Author Contributions}

Conception and design: Sallam, Toreih. Acquisition of data: Sallam, Toreih, Ibrahim, Maaty. Analysis and interpretation of data: Sallam. Drafting the article: Sallam, Maaty. Critically revising the article: all authors. Reviewed submitted version of manuscript: all authors. Approved the final version of the manuscript on behalf of all authors: Sallam. Statistical analysis: Sallam. Administrative/ technical/material support: Sallam, Hassan. Study supervision: Sallam, Hassan.

\section{Supplemental Information \\ Previous Presentations}

Portions of this work were presented as proceedings at the annual meeting of the American Academy of Orthopaedic Surgeons, San Diego, California, March 14-18, 2017.

\section{Correspondence}

Asser A. Sallam: Suez Canal University Hospitals, Ismailia, Egypt. assersallam@hotmail.com. 